\title{
Nanostructured Silicon Thin Film Electrodes for Li-Ion Batteries
}

\author{
U. Tocoglu, T. Cetinkaya, O. Cevher, M. Oguz Guler and H. Akbulut \\ Sakarya University, Engineering Faculty, Department of Metallurgical \& Materials Engineering \\ Esentepe Campus, 54187, Sakarya, Turkey
}

\begin{abstract}
In this study we produced nanostructured silicon thin films as lithium ion battery electrodes. Films were sputtered onto stainless steel substrates from high purity silicon target via dc magnetron sputtering technique with using different powers. Morphology and crystal structure of films were characterized with the use of scanning electron microscopy, X-ray diffraction and energy dispersive spectroscopy analysis, respectively. The thickness of films was measured by using surface profiler. Coin type test cells were assembled in argon filled glove box. Electrochemical performance of cells was tested on an electrochemical analyzer using constant current densities over a voltage range of $0.2-2 \mathrm{~V}$.
\end{abstract}

DOI: 10.12693/APhysPolA.123.380

PACS: 61.72.uf, 81.15.Cd, 82.47.Aa

\section{Introduction}

Rechargeable lithium (Li) ion batteries, which have lots of advantages such as high energy density, low cost and environment-friendly, are the most successful energy storage devices. Current research into Li-ion batteries is focused on enhancing its energy density and cycle life by changing the electrode materials. Silicon $(\mathrm{Si})$ is a very attractive option because it has the highest known theoretical charge capacity (about $4200 \mathrm{mAh} \mathrm{g}^{-1}$ ) [1-3]. Current $\mathrm{Si}$ anodes, however, suffer from early capacity fading caused by pulverization from the stresses induced from large volumetric changes that occur during charging and discharging. During lithiation, the Si crystal structure changes and a maximum volume expansion of $<400 \%$ may occur. The electrical contact loss because of the cracking that results from huge volume changes hinders the commercialization of $\mathrm{Si}[4-6]$. Despite the challenges of commercialization on $\mathrm{Si}$ based anodes for Li-ion batteries, a great concentrate has been focused to develop Si anodes via different forms of silicon such as, nanoparticles $[7,8]$, composites [9-12], nanowires [13, 14]. Using nanostructured silicon thin film is another reasonable way to improve cycle life of silicon anodes.

In this study thin films of silicon were deposited onto stainless substrates as Li-ion battery anodes and electrochemical performance of coin type cells was tested to determine the optimum parameters for extended life of lithium ion battery.

\section{Experimental details}

Nanostructured $\mathrm{Si}$ anodes were manufactured via dc magnetron sputtering. Pure metallic silicon has been deposited onto stainless steel substrates using three different powers. Before starting to deposition, coating chamber was evacuated to $10^{-4} \mathrm{~Pa}$ by a turbo molecular pump and then back filled with argon up to $0.5 \mathrm{~Pa}$ as working pressure. High purity metallic silicon target (99.999\% purity) having a diameter of $2^{\prime \prime}$ was used as silicon sputtering source and $150 \mathrm{~W}, 175 \mathrm{~W}, 200 \mathrm{~W}$ dc powers have been employed under argon atmosphere for deposition process. Thicknesses of films were measured by a surface profiler (Tencor P-6) and were found to be $400 \mathrm{~nm}$, $550 \mathrm{~nm}, 700 \mathrm{~nm}$ with changing dc power respectively for $150 \mathrm{~W}, 175 \mathrm{~W}$, and $200 \mathrm{~W}$. The active substance amount of films was estimated assuming that the density of silicon is $2.33 \mathrm{~g} \mathrm{~cm}^{-3}$

The crystal structures of deposited films were investigated by X-ray diffraction (XRD) (Rigaku D/MAX 2000 with thin film attachment) with $\mathrm{Cu} K_{\alpha}$ radiation. The morphology of the films was observed with scanning electron microscope (SEM, JSM-6060 LV system) and presence of silicon verified via energy dispersive spectroscopy (EDS) analysis.

Coin-type (CR2016) test cells were assembled in an argon-filled glove box, Si thin films as the working electrode, a lithium foil as the counter electrode, a micro porous polypropylene membrane (Cellgard 2400) as the separator, and $1 \mathrm{M}$ solution of $\mathrm{LiPF}_{6}$ in ethylene carbonate and dimethyl carbonate as the electrolyte. The cells were cyclically tested on a MTI Model BST8-MA electrochemical analyzer using constant current density of $800 \mathrm{~mA} / \mathrm{g}$ over a voltage range of $0.2-2 \mathrm{~V}$.

\section{Results and discussions}

No reflections except those of the chromium coated stainless steel substrate were detected by XRD analysis of the sample. Thus, the deposited silicon is considered amorphous (a-Si). It is reported that the amorphous silicon seems better than crystalline silicon for electrochemical performance of battery, because amorphous materials are more durable to volume expansions and have more open structure for $\mathrm{Li}^{+}$ion transportation [15-17]. Figure 1 represents SEM images of amorphous silicon thin 
films. It is clear from SEM images that film structure consists coarse particles approximately $1 \mu \mathrm{m}$ sized.
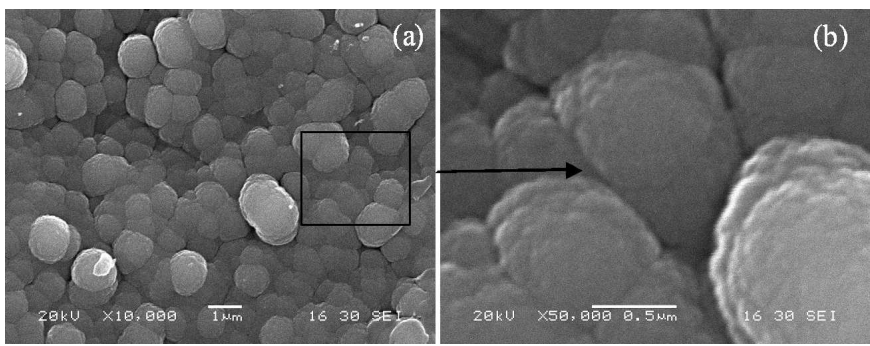

Fig. 1. Scanning electron micrograph of silicon thin films: (a) coarse particle structure seen at lower magnification, (b) the real nanosized grain structure of silicon film at higher magnification.

Also it could be seen that the film structure is not quite dense which provides more ion transportation ways. Porous structure of silicon anode makes it absorb volumetric expansion during cycling and allows the penetration of liquid electrolyte to the structure which provides high energy density [18]. Figure 1b shows the film structure at higher magnification. It is noticeable that coarse silicon particles consist of ultrafine nanoparticles.

Figure 2 shows the EDS analysis results of silicon thin film anode. It can be clearly seen from these results that the silicon atoms were dispersed homogeneously on the substrate surface. The reason of the chromium and iron presence is the stainless steel which was used in sputtering process as substrate material.

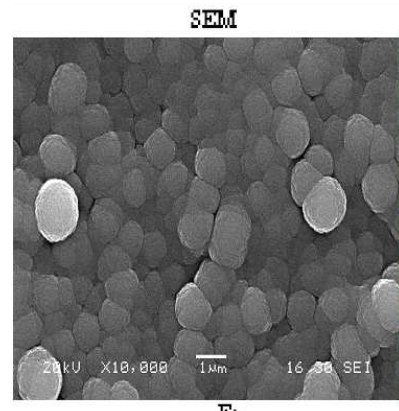

$\mathrm{Fe}$
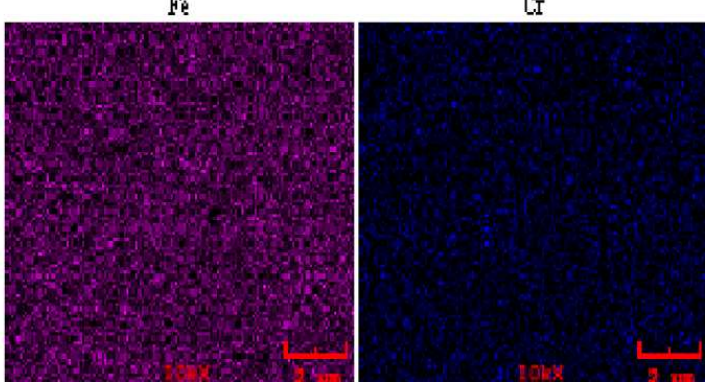

Fig. 2. EDS analysis of silicon thin film.

Three different anode materials were used in assembling of cells which were deposited at $150 \mathrm{~W}, 175 \mathrm{~W}$, and $200 \mathrm{~W}$ dc powers, respectively. Constant current densities were employed and amount of active materials estimated by assuming that film density is $2.33 \mathrm{~g} \mathrm{~cm}^{-3}$. Figure 3 shows the discharge-charge curves of Si film electrode produced at $150 \mathrm{~W}$ dc power.

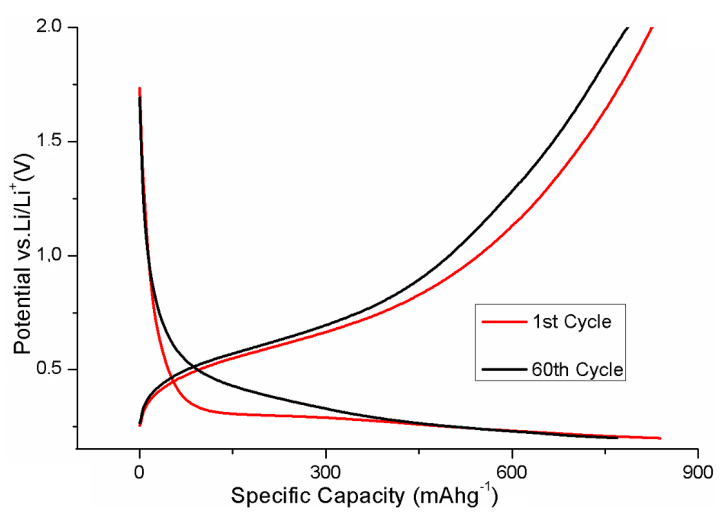

Fig. 3. The 1st and 60th galvanostatic charge and discharge plots of silicon anode at constant current density.

The first charge and discharge capacities were found to be $825 \mathrm{mAh} \mathrm{g}^{-1}$ and $865 \mathrm{mAh} \mathrm{g}^{-1}$, respectively. At the end of the galvanostatic cycling, observed capacity values were $785 \mathrm{mAh}^{-1}$ and $776 \mathrm{mAh} \mathrm{g}^{-1}$, respectively. The other anodes which were deposited at $175 \mathrm{~W}$ and $200 \mathrm{~W}$ have shown discharge capacity of $957 \mathrm{mAh} \mathrm{g}^{-1}$ and $1163 \mathrm{mAh} \mathrm{g}^{-1}$ at first cycle. Cyclic performance plots of anodes that were produced at different dc powers are represented in Fig. 4.

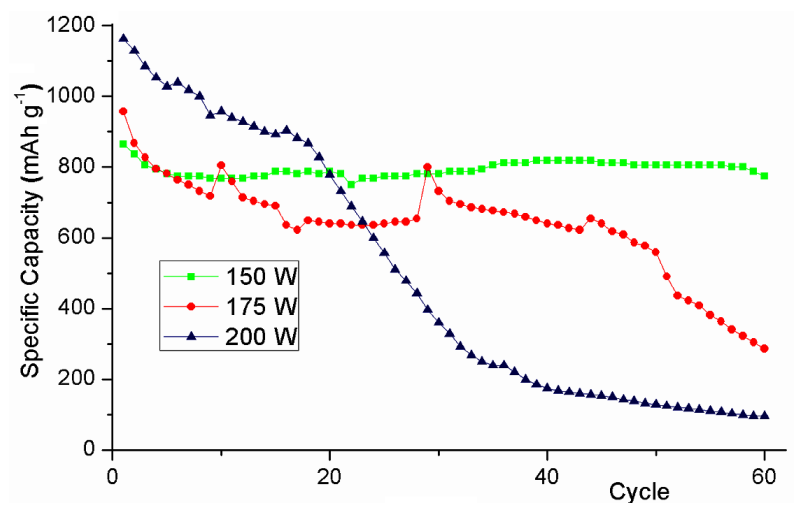

Fig. 4. Galvanostatic cycle performances of electrodes.

Cyclic performance of thinner film anode was found superior than thicker ones and showed $90 \%$ capacity retention after 60 cycles. The other anodes that have $550 \mathrm{~nm}$ and $700 \mathrm{~nm}$ thickness showed capacity retention of $30 \%$ and $9 \%$, respectively, which are poor when compared to the thinner one $[3,19]$.

\section{Conclusions}

Amorphous silicon thin film electrodes were produced and achieved almost 2.5 times more specific capacity of 
$865 \mathrm{mAh} \mathrm{g}^{-1}$ compared to the commercial graphite anodes. The thickness effect was observed to cyclic performance of battery and it was noticed that the increasing thickness of thin film caused the worse cycle performance of silicon anode.

\section{Acknowledgments}

This work is supported by the Scientific and Technological Research Council of Turkey (TUBITAK) under the contract number 111M021. The authors thank the TUBITAK MAG workers for their financial support.

\section{References}

[1] N. Ding, J. Xu, Y.X. Yao, G. Wegner, X. Fang, C.H. Chen, I. Lieberwirth, Solid State Ionics 180, $222(2009)$

[2] R. Lv, J. Yang, J. Wang, Y. NuLi, J. Power Sources 196, 3868 (2011)

[3] T.L. Kulova, A.M. Skundin, Yu.V. Pleskov, E.I. Terukov, O.I. Kon'kov, J. Electroanalyt. Chem. 600, 217 (2007)

[4] V.A. Sethuramana, K. Kowolika, V. Srinivasana, J. Power Sources 196, 393 (2011).

[5] M. Thakur, M. Isaacson, S.L. Sinsabaugh, M.S. Wong, S.L. Biswal, J. Power Sources 205, 426 (2012)

[6] C.C. Nguyen, S.-W. Song, Electrochim. Acta 55, 3026 (2010)
[7] X. Yang, Z. Wen, L. Zhang, M. You, J. Alloys Comp. 464, 265 (2008)

[8] H. Kim, B. Han, J. Choo, J. Cho, Angew. Chem. 120, 10305 (2008)

[9] X.-W. Zhang, P.K. Patil, C. Wang, A.J. Appleby, F.E. Little, D.L. Cocke, J. Power Sources 125, 206 (2004)

[10] J.-J. Cai, P.-J. Zuo, X.-Q. Cheng, Y.-H. Xu, G.-P. Yin, Electrochem. Commun. 12, 1572 (2010)

[11] Z. Luo, D. Fan, X. Liu, H. Mao, C. Yao, Z. Deng, J. Power Sources 189, 16 (2009)

[12] Z. Zhou, Y. Xu, M. Hojamberdiev, W. Liu, J. Wang, J. Alloys Comp. 507, 309 (2010)

[13] C.K. Chan, R. Ruffo, S.S. Hong, Y. Cui, J. Power Sources 189, 1132 (2009)

[14] R. Ruffo, S.S. Hong, C.K. Chan, R.A. Huggins, Y. Cui, J. Phys. Chem. C 113, 11390 (2009)

[15] V. Baranchugov, E. Markevich, E. Pollak, G. Salitra, D. Aurbach, Electrochem. Commun. 9, 796 (2007)

[16] K.-L. Lee, J.-Y. Jung, S.-W. Lee, H.-S. Moon, J.-W. Park, J. Power Sources 129, 270 (2004)

[17] L.B. Chen, J.Y. Xie, H.C. Yu, T.H. Wang, J. Appl. Electrochem. 39, 1157 (2009)

[18] C.K. Chan, R. Ruffo, S.S. Hong, Y. Cui, J. Power Sources 189, 1132 (2009)

[19] T. Moon, C. Kim, B.P. School, J. Power Sources 155, 391 (2006) 